\title{
Placebo and Nocebo Phenomena from the Perspective of Evidence Based and Person Centered Medicine
}

\author{
Miro I. Jakovljevic
}

Department of Psychiatry, School of Medicine, University of Zagreb in Clinical Hospital Centre Zagreb, Zagreb, Chroatia

\section{SUMMARY}

Introduction: Placebo and nocebo phenomena in pharmacology are very important, but controversial issues from the perspective of evidence-based medicine (EBM) in many ways.

Topic: Glorification and vilification of placebo controlled studies are the two opposite sides of the prevailing misunderstanding placebo and nocebo phenomena in medicine and pharmacology. This misunderstanding is an essential component of the pseudoscientific evaluation and evidence-based medicine. The using of placebo and avoidance of nocebo responses have been recommended as promising additional clinical strategies. The aim and purpose of this paper is to give a transdisciplinary and integrative overview of the placebo and nocebo from the perspective of person-centered medicine and also to provide some practical tips on how to increase placebo and decrease nocebo response in clinical practice.

Conclusions: Conflicting data from clinical trials and misunderstanding of placebo and nocebo phenomena are essential components of the contamination and confusion regarding evidence-based medicine. Person-centered clinical pharmacology is partly about taking advantage of placebo and avoiding of nocebo phenomena in a clinical setting as additive effects to improve the effectiveness of the standard medication.

Keywords: placebo, nocebo, evidence-based, salutogenesis, resilience, person centered, medicine, personalized, clinical pharmacology

\section{INTRODUCTION}

Treat the disease, heal the illness (Freeman 1993)

Placebo (I will please) and nocebo (I will harm) phenomena as well as evidencebased and evidence-biased medicine are subjects to an increasing and heated debate. Although history of medicine is history of placebos, placebos have still a bad reputation in modern scientific medicine. On the other side nocebos, common not only in clinical tri- als, but also in clinical practice, are frequently unrecognized. According Sartorius (2009) "placebo was first used to describe a commonplace treatment, then a treatment intended to 'please, not cure', and today to label a substance without a specific effect - at best to describe the inactive control substance in clinical trials, and at worst to describe a toll in a charlatan's arsenal" [1]. During the last 10-15 years the use of placebo therapeutics in clinical situations, as well as placebo controls in randomized clinical trials (RCT), has been criticized as 
unethical deception and coercion of patients. Furthermore, until recently nocebo was unknown to majority of health care professionals and the data on it are still scarce [2]. Summaries of Product Characteristics (SPC) of drugs are silent about nocebo reactions to drugs what makes problems with informed consents. Nocebo phenomena distress patients, add to the burden of their illness, increase the cost of care, lead to non-adherence or discontinuation of otherwise an appropriate treatment, trigger prescription of additional drugs to treat unrecognized nocebo response [3]. Between $4 \%$ and $26 \%$ of patients in RCTs randomize to placebo arm discontinued the trial because of perceived adverse events [3]. Clinical trials investigating the nocebo response induction are generally considered unethical because they harm. Useful information can be obtained by analysis of adverse events related to placebo arm in regular RCTs. Placebo and nocebo are nemesis for clinical trials and evidence-based medicine (EBM) in many ways and represent a huge challenge to modern clinical pharmacology. They tell us a lot about the complexity of healing and have very important implications on our understanding of EBM, performing clinical trials and treatment guidelines. Placebo is essential for the scientific evaluation of health care interventions which is a cornerstone of the EBM. Problems in scientific evaluating of therapeutic effects and side effects of any treatment may be related to placebo and nocebo response misunderstanding. On the other side, EBM is expected to investigate and explain different mediating and modulating placebo and nocebo mechanisms, rely on academic clinical trials [4]. Conflicting data and misunderstanding of placebo and nocebo phenomena are essential components of the pseudoscientific evaluation and evidence-biased medicine.

Evidence-based approach in contemporary pharmacotherapy raises series of epistemological, explanatory, legal and ethical questions regarding placebo and nocebo. Better scientific understanding mechanisms behind placebo and nocebo phenomena and learning how to harness their effects in clinical practice are crucial precondition for joining evidencebased practice and practice-based evidence in order to increase treatment effectiveness in many fields of clinical pharmacology, especially in hospital pharmacology. Despite the significant progress that placebo and nocebo research has made over recent decades, particularly in the neurobiology and psychodynamics of placebo and nocebo response, many questions and dilemmas still remain open.

The aim and purpose of this paper is to give a transdisciplinary and integrative overview of the current research and understanding of the placebo and nocebo from the perspective of person-centered medicine and also to provide some practical tips on how to increase placebo and decrease nocebo response in clinical practice.

\section{Placebo and nocebo phenomena and evi- dence-based vs. evidence biased medicine}

Double-blind placebo-controlled studies have been a hall mark of evidence-based medicine (EBM) which has been proclaimed as the highest standard of health care. However, distinctions should be made between the EBM as an ideal paradigm and the EBM as it is implemented in everyday clinical practice that often in some fields looks like evidence-biased medicine or pseudo-science based medicine. The fact is that EBM has significantly improved practice in some specific areas, like, e.g. stroke and myocardial infarction aftercare. However, in the last years there has been an increasing number of warning reports "that in modern research, misrepresented, false and un-useful findings may be the majority or even the vast majority of published research claims" [ $5,6,7,8,9,10,11]$. Some authors claim that EBM is failing due to biased trials and selective publication [12]. Pseudoscience and evidence biased medicine represent a serious threat to clinical pharmacology and drug treatment guidelines [13]. From time to time media have been occupied with big scandals like: "Statins are the greatest medical fraud of all time", "Why Big Pharma wants you to be afraid of cholesterol", "Making something out of nothing at all: Statistical magic in drug marketing", "Cohrane reviews have shown that it is doubtful whether antidepressants are effective for depression and whether antipsychotics are effective for schizophrenia", "Antidepressants have no benefit over placebo", "Listening to Prozac, but hearing placebo", which have attracted public attention and promote negative response to drug treatments. Understanding non-pharmacological factors involving placebo and nocebo phenomena that positively or negatively influence drug treatment response is fundamental 
for improving EBM and proper understanding science-based medicine (SBM).

Here, a thorny question arises as to what is evidence and how we know what is it proper evidence. According to the Encarta Concise Dictionary, Student Edition (2001) evidence means "something that gives sign or proof of the existence or truth of something, or that helps somebody to come to a particular conclusion" [14]. The last meaning "something that helps somebody to come to a particular conclusion" means also facts, testimony and proof in support of a statement, claim or belief. But collected facts and data do not speak for themselves alone; they are subjects to varying thinking strategies and information processing depending on who is doing the information processing. Evidence as well as treatment effectiveness is always context dependent, as well as placebo and nocebo responses. The limitations of the science base including doubleblind randomized controlled trials (RCTs) on which EBM stands should be acknowledged. According to Mitsikostas et all, dropouts due to nocebo responses may put into question the results of many RCTs [15]. The majority of the large RCTs undertaken in clinical pharmacology are sponsored by the pharmaceutical industry with the aim to demonstrate to regulatory agencies the efficacy of investigated drug over placebo ( Table 1).

On the other side, there are significantly less natural, pragmatic or observational studies demonstrating the effectiveness of drug in the real clinical context on the real patients' population which is more heterogenous and

Table 1. Examples of methods for pharmaceutical companies to get the results they want from clinical trials [12]
Conduct a trial of your drug against a treatment known to be inferior

Trial your drugs against too low a dose of a competitor drug

Conduct a trial of your drug against too high a dose of a competitor drug (making your drug seem less toxic)

Conduct trials that are too small to show differences from competitor drugs

Use multiple end points in the trial and select for publication those that give favorable results

Do multicenter trials and select for publication results from centers that favorable

Conduct subgroup analyses and select for publication those that are favorable

Present results which are most likely to impress - for example, reduction in relative rather than absolute risk with severe disorders than those in registration RCTs [16]. Furthermore, negative studies are very rarely published, so that what we call EBM in the form of guidelines and algorithms may be biased and become evidence-biased medicine[17]. It is a warning claim that $90 \%$ of trials showed superiority of the sponsor's drug [18] what can explain "Why olanzapine beats risperidone, risperidone beats quetiapine, and quetiapine beats olanzapine"[ 19]. Several large independent studies like CATIE (Clinical Antipsychotic Trials of Intervention Effectiveness), CUtLASS (Cost Utility of the Latest Antipsychotic Drugs in Schizophrenia), and EUFEST (European First Episode Study) have found that the new generation antipsychotics are no more effective, no better tolerated and are less cost effective than their old generation predecessors $[20,21,22,23]$. Some independent meta-analyses pooling unpublished as well as published data indicated that SSRIs were no more effective than placebo in treating mild-to-moderate depression $[24,25]$. Today more and more authors speak about "evidence-based quackery" and "contamination of EBM by researchers not addressing the proper questions with appropriate studies" and "call for a renaissance .... in the form of " real evidence-based medicine', refocusing on a critical examination of the pros and cons of the evidence which can be combined with context and professional expertise in concrete circumstances" [26]. The individual patient needs the idiographic patient-based evidence which refers to known data about diagnostic markers and the specific and differential effectiveness of various drugs or treatment methods to that particular individual. Non-adherence to drug treatment and non-cooperation of patients may be related to nomothetic impersonal and technical rationality followed by nocebo response [27]. Some studies have also stressed a decreasing quality of published literature due to an increasing competition for grants and jobs, the current mania for publishing papers and a disproportionate emphasis on quantity over quality in scientific outputs, huge administration, and overreliance on reductionism [10], linear, mechanistic and formistic information processing. EBM's aims to improve health-care effectiveness and efficiency have been thwarted by bias in the choice of hypotheses tested, manipulation of study design and selective publication, particularly in industryfunded trials [18]. 
Placebo and nocebo between myths and facts: Explanatory models

Placebo and nocebo have been usually viewed in pharmacology through reductionist lenses. Although they are fascinating and universal social, cultural and psychobiological phenomena many people misunderstand them. In medicine, placebo and nocebo phenomena are usually defined as positive or negative nonspecific psychological and physiological responses to inert substance or irrelevant procedure. A placebo is an inert substance, while placebo or nocebo response is positive or negative reaction that follows administration of an inert substance. However, placebo and nocebo phenomena are genuine phenomena that can more or less affect everyone and every kind of treatment. These phenomena have potential to powerfully improve or worsen mental or somatic symptoms without official or proven medical or psychotherapeutic intervention. The very important fact is that placebo and nocebo response may appear in any kind of medical and psychosocial treatment. Each medical treatment including psychotherapy may be associated with psychologically pleasing (placebo - latin word "I shall please) or negative harming (nocebo - latin word "I shall harm) response which can significantly modify the overall treatment outcome so these phenomena are of great importance for medicine in general. According to "the Dodo bird verdict" in psychotherapy $40 \%$ of change comes from patients' personal resources, both psychological and environmental, 30\% from common features of therapists such as empathy, warmth, acceptance and encouragement, $15 \%$ from patients' trust and expectation, sometimes called placebo, and $15 \%$ from the therapist's specific techniques and theoretical models [28]. The placebo and nocebo phenomena represent a

The individual, personality differences model: placebo and nocebo "responsiveness" may be related to the certain types of personalities so that one can speak about placebo reactors and nocebo reactors (placebo-prone and nocebo-prone personality) factors such as dispositional optimism, hypnotic suggestibility, somatic focus, empathy, neuroticism, altruism, social desirability, dopamine-related traits, fear of pain, locus of ego-resilience, anxiety, pessimism, pain catastrophizing, harm avoidance, and persistence have been linked to placebo and nocebo effects.

The interpersonal dynamics model: placebo and nocebo responsiveness should be understood in terms of the complex dynamics of the physician-patient relationship. Some physicians are themselves powerful placebos: Central components in all healer-patient relationships such as hope, trust, caring, empathy, and compassion play an important role in placebo response.

The perceptual filtering model: Placebo and nocebo responsiveness can be explained in terms of patients' positive or negative perceptual filtering and misattribution. Patients with placebo response are typically motivated to get better and to please their physicians, and in doing so they tend to foreground beneficial changes. In addition, they frequently filter out negative changes and outcomes.

The neurobiological model: Placebo and nocebo responsiveness can be understood in neurobiological terms as the activation of the different psychophysiological and neurotransmitters systems. E.g. Placebo and nocebo phenomena are related to the opposite responses of dopaminergic and endogenous opioid neurotransmissions in various brain areas, as well as of the brain reward - punishment system.

The conditioning model: Placebo and nocebo responsiveness can be explained in the terms of classical conditioning theory because they resembles to a positive or negative conditioned stimulus. They can be related to non-conscious associative learning processes and priming effects.

The meaning making model: Placebo and nocebo responsiveness can be understood in terms of cultural practices of positive and negative meaning making. Placebo is positive, and nocebo negative meaning response.

The logic of expectation model: Placebo and nocebo responsiveness can be explained in terms of a logic of expectation in which cultural conceptions of the effectiveness of medications, or imagined expectations, can override their pharmacological action. Patients' knowledge about and expectations of a treatment affect the treatment outcome.

The narrative pharmacology model: The patient's beliefs and stories concerning the origin of symptoms and medicines action may contribute positively (placebo) or negatively (nocebo) to drug treatment response

The resilience model: Beliefs, actions and behavior may have salutogenic or pathogenic effects. Resilience is a protective collection of thoughts, actions and behavior that can be developed and improved by everybody. Thus, placebo effect can be understood as a form resilience activating or enhancing by treatment.

The multidimensional integrative model: Includes all above models based on trans-disciplinary systemic approach

Table 2. Explanatory models of placebo and nocebo effects and responses $[3,30,31,32,33]$ 
very good model for our better understanding the role of treatment context and how the words, thoughts, meanings, images, beliefs, anticipations and expectancies act on our brain and mind producing positive or negative health effects [29].

For proper understanding of placebo and nocebo phenomena in pharmacology it is of great importance to be familiar with quite a number of explanatory models which can be identified in scientific literature (Table 2) In order to benefit from better understanding of placebo and nocebo phenomena, it is important to establish a culture in the daily medical practice, in which physicians are familiar with the potential of these mechanisms and master strategies on how to manage these phenomena to increase the quality of research and clinical practice $[34,35]$. Goal-oriented utilization of placebo responses may contribute to overall drug treatment effectiveness while having in mind and preventing nocebo responses may provide a useful possibility to reduce adversary events.

\section{Placebo and nocebo from the perspective of the person-centered medicine}

"It is more important to know what kind of a patient has a disease than what kind of a disease a patient has" (William Osler)

Placebo and nocebo might be considered as the personal responses to any kind of treatment, so they are very important phenomena from the perspective of the personcentered medicine. Patients are always subjects who give sense and respond more or less actively to meanings that disease, illness and treatment have for them and their physicians. Concept of person-centered pharmacotherapy supports a shift from impersonal disease model and demoralizing prognostic skepti-
Table 3. Rational (conventional) pharmacotherapy vs. Person-centered pharmacotherapy $[36,37]$

\section{Traditional pharmacotherapy}

- Standardized, based on knowledge and research, impersonal and dismissive of individuality

- Epidemiological, nomothetic in the spirit of modern science philosophy

- Based on linear and mechanistic thinking and deductive logic

- Self-determination of patients reduced.

- Patients' compliance is expected or requested.

- Only physicians have access to information (e.g., drug treatment plans, assessments, records, etc.).

Doctors know the best.

- Focus is on pathology (disease or illness), weakness and disadvantages

- Symptoms, dysfunctions, disabilities, deficits drive treatment.

- Patients are more objects of treatment.

- Clinical (symptomatic and functional) remission/recovery is valued.

- Drug treatment is defined by treatment guideline.

- Avoidance of risk ("Primum non nocere"). Protection of patient and community.

- Statistical evidence-based practice

- Negative view on placebo component of treatment, regarded as a nuisance or a barrier to rational approach

\section{Person-centered pharmacotherapy}

- Pluralistic, based on wisdom, research and practice, personal and respective of individuality (an art based on the science)

- Individualistic and more humanistic in the spirit of postmodern science philosophy

- Based non only on rational thinking and deductive logic, but also on systemic and lateral thinking, imagination and inductive logic

- Self-determination of patients is promoted.

- Alliance is much more than compliance. Patients' active participation and personal mastery is essential.

- Patients and their families have also access to the information. Doctors and patients together know

the best. Shared treatment vision and decisions.

- Patients are best experts on their life

- Focus on self-actualization, health and quality of life, strengths and advantages

- Therapeutic goals drive treatment.

- Patients are more subjects, active participants and stars of treatment

- In addition to clinical and personal recovery is valued

- Drug treatment is rooted in creative and systematic thinking (art and practice of learning organiza-

tion)

- Responsible risk-taking and personal growth. Avoid risk, whenever is possible.

- In addition to evidence-based practice, value- and narrative-based practice

- Positive view on placebo treatment, eliciting placebo response, preventing nocebo response

- Resilience promoting and enhancing treatment

- Promoting salutogenesis, stopping and decreasing patogenetic processes 
cism towards optimism and personal recovery broadening treatment goals beyond symptom reduction and elimination. Person-centered pharmacotherapy is not a competitor to traditional, evidence-based pharmacotherapy (Table 3); they are a complementary duality, as intimately connected as brain and soul $[36,37]$. While the physician is an expert with specialized knowledge about drug treatments, the patient is the expert on his or her life, and the best judge of the treatment outcome. Patients always bring into treatment unique characteristics related to their vulnerability, resilience and potential for personal growth as well as proneness to placebo or nocebo responsiveness. Disease has to be treated, but the needs of the suffering person have also to be met, helped with and healed. So person-centered pharmacotherapy is a part of personal recovery oriented treatment. Treatment that focuses only on symptoms elimination and decreasing illness may be like the tail wagging the dog. In addition to decrease illness it is very important to increase wellness and well-being. Patients need to learn specific skills of positive psychology: how to have more positive thinking and emotions, more novelty seeking and engagement, more gratitude, love and sense of life, more accomplishment, and better human relations [38].

Each patient should get highly specific and individually adjusted drug treatment in given circumstances [39]. Generally speaking, the optimal treatment regime, in terms of drug selection, dosage, duration, effectiveness (efficacy and tolerability) should be individualized (tailor made for the individual) and personalized (person-centered). Pharmacotherapy is usually a context dependent practice because different contexts at many levels reflect the contribution and meaning of biological variables in different ways. It is an important fact that "the genome operate within the context of the cell, the cell within the context of the body, the body within the context of the self, the self within the context of the society, the society within the context of the cosmos" [40]. The close interconnectedness of the spirit, mind, brain, endocrine and immune systems suggests a self-aware "operating and healing system" of human beings, which works silently in the background regulating and coordinating all living processes. Activation of this healing system is followed by the placebo response. Person-centered pharmacotherapy is firmly associated with creating a favorable treatment context which promotes therapeutic alliance and partnership that "pleases" the patient. Creating a favorable treatment context and enhancing resilience is in fact a placebo-maximizing and nocebo-minimizing/preventing practice [41].

The creation of favorable therapeutic context is significantly associated with active participation of patients and their commitment to treatment. The purpose of person-centered pharmacotherapy is to impove the patients to control their disease, to obtain full personal recovery and to regain control over their life. However, taking medications only is often not enough for full treatment success. Pharmacotherapy as a sole form of treatment may carry the wrong message that patients don't have to change their life style and don't have to learn any new skills, they just have to receive their medication on time because the only problem is in brain chemistry. Pharmacotherapy is one essential external support, alongside a whole range of other type of resilience-promoting supports, skills and strengths. The goals of medication treatment are not only to decrease illness and prevent relapse, but also to help patients learn new ways of thinking, emotional response and behavior to get more love, freedom, power, joy and sense of life. Learning in this context does not mean getting more information, but expanding the ability to produce the results truly wanted. Improving personal mastery, involving self-care and self-management of patients goes beyond competence and skills, as well as beyond spiritual unfolding or opening, it means living life from a creative as opposed to reactive viewpoint [42]. Creative collaboration with patients and their families includes building the shared treatment goals as well as the pictures of their future that foster their genuine commitment and enrollment more than simple compliance. Alliance is much more than compliance. A shared vision is the first step in allowing people who mistrusted each other to begin to work together [42]. Motivational interviewing with matching, pacing and leading techniques, is an essential step in establishing a creative treatment context because it helps the patients to articulate personally meaningful goals, while taking medications may facilitate achieving their goals. Being able to set and pursue personal goals provides much of the motivation for better cooperation and active participation in treatment. As patients develop more personal mastery over their symptoms, they become able to bet- 
ter master over their lives and to realize their own vision of recovery. Creating and fostering hope, meaning, personal responsibility, spirit of optimism and commitment can significantly contribute to overall positive response to pharmacotherapy, but in the other way round drug treatment can contribute to creation and fostering hope, meaning, personal responsibility, spirit of optimism and commitment. Hope, which includes perceived external resources, perceived internal resources and positive expectations, is recognized as the starting point for personal recovery. Patients with high hope are more likely to cope successfully with future adversity. Personal recovery involves a journey from disengagement to engagement, from surviving to living and growing, it has many routes and each patient's journey is unique with taking back control over own life and finding hope for a better future [43]

\section{CONCLUSION}

Understanding the mechanisms behind placebo and nocebo phenomena is very important for all physicians for proper application of the EBM, effective treatment and person-centered pharmacotherapy. Placebo should not be bane to research if researchers strive to potentiate the placebo response in all investigated groups. On the other side, if properly handled, placebo phenomena are surely a boon to therapy. The using of placebo and avoidance of nocebo responses have been recommended as promising additional clinical strategies. The concept of salutogenesis and resilience offers a framework for eliciting placebo responses and positive outcomes, and minimizing nocebo response and negative outcomes in patients with different disorders and illnesses. Personcentered pharmacology is partly about taking advantage of placebo and avoiding of nocebophenomena in a clinical setting as additive effects to improve the effectiveness of the standard medication.

\section{REFERENCES}

1. Sartorius N: Praised be placebo, may its glory shine. In Sartorius N: Pathways of Medicine. Medicinska naklada, Zagreb. 2009.

2. Haeuser W, Hansen E \&Enck P: Nocebo phenomena in medicine: Their relevance in every day clinical practice. Dtsch Arztebl Int 2012; 109:459-465.

3. Planes S, Villier $C \&$ \&allaret $M$ : The nocebo effect of drugs. Pharma Res Per 2016, 4(2), e00208, doi:10.1002/prp.208

4. Marković SZ, Kastratović DA, Kubiak C, Demotes Mainard J. ECRIN - Needed in European Science. Hospital Pharmacology - International Multidisciplinary Journal. 2015; 2(2):279-282. ( www. hophonline.org )

5. loannidis JPA: Why most published research findings are false. PLOS medicine 2005; 2: e124.a

6. Ioannidis JPA: Why most published research findings are false. CHANCE 2005; 18:40-47. doi:10.1080 /09332480.2005.10722754. b

7. Fanelli D: How many scientists fabricate and falsify research? - A systematic review and meta-analysis of survey data. PLOS ONE 2009:4(5): e5738. doi:10.1371/journal.pone.0005738

8. Boutron I, Dutton S, Ravaud P \& Altman DG: Reporting and interpretation of randomized controlled trials with statistically nonsignificant results. JAMA 2010; 303:2058-64.

9. loannidis JPA: How to make more published research true. PLOS medicine 2014; 11(10): e1001747 doi:10.1371/journal.pmed.1001747.

10. Bowen A, Casadevall A: Increasing disparities between resource inputs and outcome, as measured by certain health deliverables, in biomedical research. PNAS 2015; 112:11335-11340. www.pnas. org/cgi/doi/10.1073/pnas.1504955112.

11. Ioannidis JPA: Why most clinical research is not useful. PLOS medicine 2016; 13(6): e1002049. doi:10.1371/journal.pmed.1002049

12. Every-Palmer $\mathrm{S} \&$ Howick J: How evidence-based medicine is failing to biased trials and selective publication. Journal of Evaluation in Clinical Practie 2014: 20. 908-814.doi:10.1111/jep.12147

13. Jakovljevic M \&OstojicLj: Science and pseudoscience inmedicine: Evidence based vs. evidence biased medicine. PsychiatriaDanubina 2016; 28(suppl 2);s186-s190. Medicina Academica Mostariensia 2016; 4:2-6.

14. Encharta Concise Dictionary, Student Edition, Bloomsbury Publishing Inc, London 2001.

15. Mitsikostas DD, Mantonakis LI \&Chalarakis NG: Nocebo is the enemy, not placebo. A meta-analysis of reported side effects after placebo treatment in headaches.Cephalgialnt J Headache 2011; 31:550561.

16. Jakovljevic M: New generation vs. first generation antipsychotics debate: Pragmatic clinical trials and practice based evidence, Psychiatria Danubina 2009; 21:446-452.

17. Jakovljevic M: Myths and facts in contemporary psychopharmacotherapy: evidence-based vs. evidence-biased treatment algorithms practice. Psychiatria Danubina 2007; 19:342-349.b

18. Every-Palmer S, Howick J: How evidence-based 
medicine is failing to biased trials and selective publication. Journal of Evaluation in Clinical Practie 2014: 20. 908-814.doi:10.1111/jep.12147

19. Heres S, Davis J, Maino K, Jetzinger E, Kissling W \& Leucht S: Why olanzapine beats risperidone, risperidone beats quetiapine, and quetiapine beats olanzapine. American Journal of Psychiatry 2006; 163:185-194.

20. Lieberman JA, Stroup TS, McEvoy JP, Swartz MS, Rosenheck RA, Perkins DO, Keefe RS, Davis SM, Davis CE, Lebowitz BD, Severe J, Hsiao JK; Clinical Antipsychotic Trials of Intervention Effectiveness (CATIE) Investigators. : Effectiveness of antipsychotic drugs in patients with chronic schizophrenia. New England Journal of Medicine 2005; 353:1209-1223.

21. Rosenheck RA, Leslie DL, Sindelar, et al.: Costeffectiveness of second generation antipsychotics and perphenazine in a randomized trial of treatment for chronic schizophrenia. American Journal of Psychiatry 2006; 163:2080-2089.

22. Jones PB, Barnes TR, Davies L, et al.: Randomized controlled trial of the effect of life of second versus first generation antipsychotic drugs in schizophrenia: Cost Utility of the Latest Antipsychotic Drugs in Schizophrenia Study (CUtLASS). Archives of General Psychiatry 2006; 63:1079-1087.

23. Kahn RS, Fleischhacker WW, Boter H, Davidson $M$, Vergouwe Y, Keet IP, Gheorghe MD, Rybakowski JK, Galderisi S, Libiger J, Hummer M, Dollfus S, López-lbor JJ, Hranov LG, Gaebel W, Peuskens J, Lindefors N, Riecher-Rössler A, Grobbee DE; EUFEST study groupEffectiveness of antipsychotic drugs in first-episode schizophrenia andschizophreniform disorder: an open randomized clinical trial. The Lancet 2008; 371:1085-1097.

24. Kirsch I, Deacon BJ, Huedo-Medina TB, Scoboria A, Moor TJ, Johnson BT. Initial severity and antidepressant benefits: a meta analyses of data submitted to the Food and Drug Administration. PLoS Medicine 2008; 5, e45.

25. Fournier JC, DeRubeis RJ, Hollon SD, Dimidjian $S$, Amsterdam JD, Shelton RC, Fawcett J. Antidepressant drug effects and depression severity: a patient level meta-analysis. Journal of the Ameican Medical Association 2010; 303:47-53.

26. Naudet F, Falissard B, Boussagen R \& Healy D: Has evidence based medicine left quackery behind. Intern Emerg Med 2015; 10:631-634. DOI 10.1007/ s11739-015-1227-3

27. Jakovljevic M: Theoretical psychiatry: Missing link between academic and clinical psychiatry for further scientific and professional maturation of psychiatry. PsychiatriaDanubina 2013; 25:203-206.

28. Lewis B: Narrative Psychiatry - How Stories Can Shape Clinical practice. The Johns Hopkins University press, Baltimore, 2011.

29. Benedetti F, Armanzio M: The placebo response: How words and rituals change the patient's brain. Patient Education and Counseling 2011; 84:413-
419.

30. Jopling DA: Talking Cures and Placebo Effects. Oxford University Press, 2008.

31. Jaksic N, Aukst-Margetic B \& Jakovljevic M: Does personality play a relevant role in the placebo effect? PsychiatriaDanubina 2013; 25:17-23.

32. Jakovljevic M. The placebo-nocebo response: Controversies and challenges from clinical and research perspective. European Neuropsychopharmacology, 2014a; 24: 333-341.

33. Corsi $N$ \&Colloca L: The placebo and nocebo effects: The advantage of measuring expectations and psychological factors. Frontiers in Psychology Published online 2017 Mar6.doi:10.3389/ fpsyg.2017.00308

34. Kamperman L, Nestoriuc Y \&Shedden-Mora MC: Physicians' beliefs about placebo and nocebo effects in antidepressants - an online survey among German practicioners. 2017; PLoS One 12(5):e0178719. https:/doi.org/10.1371/journal, pone.0178719

35. Chavarria V, Vian J, Pereira C, Data-Franco, Fernandes BS, Merck M \&Dod S: The placebo and nocebo phenomena: Their clinical management and impacz on treatment outcomes. Clinical Therapeutics 2017: 39:477-486.

36. Jakovljevic M: Person-centred psychopharmacotherapy: What is it? Each Patient is a unique, responsive and responsible subject. Psychiatria Danubina 2015; 27 (suppl 1):28-33.

37. Jakovljevic M , Abou-Salex MT: Person Centered Psychopharmacotherapy. In Mezzich JE, Botbol M, Christodoulou GN, Cloninger CR \&Salloum IM (eds): Person Centered Psychiatry, 235-245. Springer, 2016.

38. Seligman MEP: Flourish - A Visionary New Understanding of Happiness and Well-being. Free Press, New York, 2012.

39. Jakovljevic M: The creative psychopharmacotherapy and personalized medicine: The art \& practice of the learning organization. Psychiatria Danubina 2010; 22:309-312.

40. Cloninger CR: Feeling Good: The Science of Well-being. Oxford University Press, Oxford, 2004.

41. Jakovljevic M. The placebo-nocebo response in patients with depression: do we need to reconsider our treatment approach and clinical trial designs? Psychiatria Danubina, 2014b; 26:92-95.

42. Senge PM: The Fifth Discipline - The Art and Practice of the Learning Organisation. Random House, London, 2006.

43. Leamy M, Bird V, Le Boutillier C, Williams J, Slade $M$. Conceptual framework for personal recovery in mental health: systematic review and narrative synthesis. Br J Psychiatry. 2011 Dec;199(6):44552. doi: 10.1192/bjp.bp.110.083733. 


\section{Persektiva placebo i nocebo fenomena u evidence based i personalizovanoj medicini}

Miro I. Jakovljevic

Klinika za psihijatriju, Kliničko-bolnički centar Zagreb, Medicinski fakultet Univerziteta Zagreb, Zagreb, Hrvatska

\section{KRATAK SADRŽAJ}

Uvod: Placebo i nocebo fenomen su veoma značajni u farmakologiji. Pripadaju kontraverznoj oblasti iz ugla evidence-based medicine na mnogo načina.

Tema: Glorifikacija i potcenjivanje placebo kontrolisanih studija su dve suprotne strane postojeċeg nesporazuma oko placebo i nocebo fenomena u medicini, posebno kliničkoj farmakologiji. Ovaj nesporazum je esencijalna komponenta pseudonaučne evaluacije i evidence-based medicine. Upotreba placeba i izbegavanje nocebo odgovora su preporučene kao obeċavajuċa klinička strategija. Cilj i svrha ovoga revijalnog rada je multidisciplinarni i integrativni prikaz perspective placeba i noceba u personalizovanoj medicini, kao i neke praktične preporuke kako da se poveca placebo i smanji nocebo odgovor u kliničkoj praksi.

Zaključak: Konfliktni podaci iz kliničkih studija i nerazumevanje placebo i nocebo fenomena su esencijalne komponente kontaminacije i konfuzije u odnosu na evidence-based medicinu. Personalizovana klinička farmakologija može da pruži šansu placebu i izbegne nocebo fenomen u kliničkoj praksi u cilju unapredjenja efikasnosti standardne terapije.

Ključne reči: placebo, nocebo, evidence-based, salutogeneza, rezilijencija, personalizovana, medicina, klinička farmakologija 